IOSR Journal of Engineering (IOSRJEN)

e-ISSN: 2250-3021, p-ISSN: 2278-8719

Vol. 3, Issue 8 (August. 2013), ||V4 || PP 06-09

\title{
Answer to the Call-for-help on the Flammability Nature of Rural Housing
}

\author{
Odinma, S.C., Eboatu, A.N., Arinze, R.U. and Okoye, N.H. \\ (Department of Pure and Industrial Chemistry, Nnamdi Azikiwe University, P.M.B. 5025 Awka Anambra State \\ Nigeria)
}

\begin{abstract}
Di-ammonium Hydrogen Phosphate hereafter referred to as fertilizer and Potassium Aluminum Sulphate as Alum, were used as flame-retardant compounds on a grass commonly use as a roofing thatch. It was observed that the incorporation of these chemical compounds dramatically reduced the flame propagation rate, flame duration time and after-glow time while the ignition time and Add-on (\%) increased. These results are interpreted on the fact that on heating, these chemical compounds evolve substances that compete with the burning behavior of the grass.
\end{abstract}

Keywords: - Char formation, Combustion, Flammability, Flame retardant, and Roofing thatch.

\section{INTRODUCTION}

According to estimate [1] rural housing provides shelter for over 70\% of Africans. Prior to civilization, these houses have been roofed with thatch. The usefulness of thatch has not changed/altered by the inventions of either corrugated iron sheeting or the bricks and slates. This is because thatch posses healthy nature [2-3] which include: (i) excellent acoustic, electrical and thermal isolation, (ii) protection from the most dangerous part of the UV spectra, (iii) Freedom in shaping, (iv) Perfect harmony with the environment and landscape, (v) cooler in summer, warmer in the winter (vi) It is beautiful and natural (vii) chip and demand less technology etc. Though thatch material has one horrible disadvantage which when dry ignite sharply and burns mercilessly. Hence the need to reduce this problem becomes our fundamental aim and objective. In this article we reported on the effect Alum and Fertilizer on the flammability nature of a roofing thatch known as Schizachyrium sanguineum.

\subsection{Materials}

\section{EXPERIMENTAL}

The grass studied is Schizachyrium sanguineum commonly used as roofing thatch in Nsukka Enugu State, Nigeria. It is referred to by its Igbo name as Irure. Potassium Aluminum Sulphate, $\left(\mathrm{K}_{2} \mathrm{SO}_{4}\right.$. $\left.\mathrm{Al}_{2}\left(\mathrm{SO}_{4}\right)_{3} .24 \mathrm{H}_{2} \mathrm{O}\right)$ was procured from the Federal Superphosphate Fertilizer plant at Kaduna Nigeria and Diammonium Hydrogen Phosphate $\left.\left(\mathrm{NH}_{4}\right)_{2} \mathrm{HPO}_{4}\right)$ procured from M\&B Laboratory Chemicals Dagenham, England. All chemicals were used as supplied by the manufacturers.

\subsection{Method}

(a) Flame-retardant treatment: the thatch sample was sun dried for few days and finally cured in electric oven at $105-110^{\circ} \mathrm{C}$ to constant weight. The dry samples were completely immersed in equal volumes but different concentrations of flame-retardants contained in $1000 \mathrm{~cm}^{3}$ measuring cylinder, for 2days. On removal from the solution, materials were again dried to constant weight in the electric oven $\left(105-110^{\circ} \mathrm{C}\right)$. Thus the weight of flame-retardant absorbed by samples was determined, using the expression [4]:

Add-on $(\%)=[(\mathrm{Y}-\mathrm{X}) / \mathrm{X}] \times 100 / 1$

Where $\mathrm{Y}=$ weight of the sample after treatment

$\mathrm{X}=$ weight of the sample before treatment.

(b) Determination of Ignition Time (I.T): the sample was clamped at $45^{\circ}$ such that a constant distance is maintained between its lower tip and small cigarette lighter. The time interval between the sample touching flame and ignition (indicated by an initial tiny spark) was regarded as the ignition time. Fifteen (15) readings per sample were taken and the average calculated.

(c) Determination of flame propagation rate (F.P.R): The distance covered by the char-front at a giving time interval is regarded as FPR. The sample was clamped at $45^{\circ}$ and was ignited at the base in a room with no air current.

Flame propagation rate $(\mathrm{cm} / \mathrm{s})=[$ distance moved by charfront $(\mathrm{cm})] /[$ time $(\mathrm{s})]$.

(d) Determination of flame duration time (F.D.T): is the time lapse between ignition and self extinguishment. 
(e) Determination of After Glow time (A.G.T): this was taken as the time between flame-out and the last visually perceptible glow [3]. Again, for each sample five readings were taken and the average found/calculated.

\section{RESULTS AND DISCUSSION}

The result of the percentage add-on of the flame-retardants is shown in Fig.1. It is clear that the quantities of flame-retardants absorbed by this thatch material depend on the liquor concentration.

In a system, i.e. polymerics, including cellulosics, the manner of chemisorption is well represented by the Fick's Laws [5, 6]. On the basis of this fact, the observation highlighted in Fig.1 is in accord with theoretical considerations.

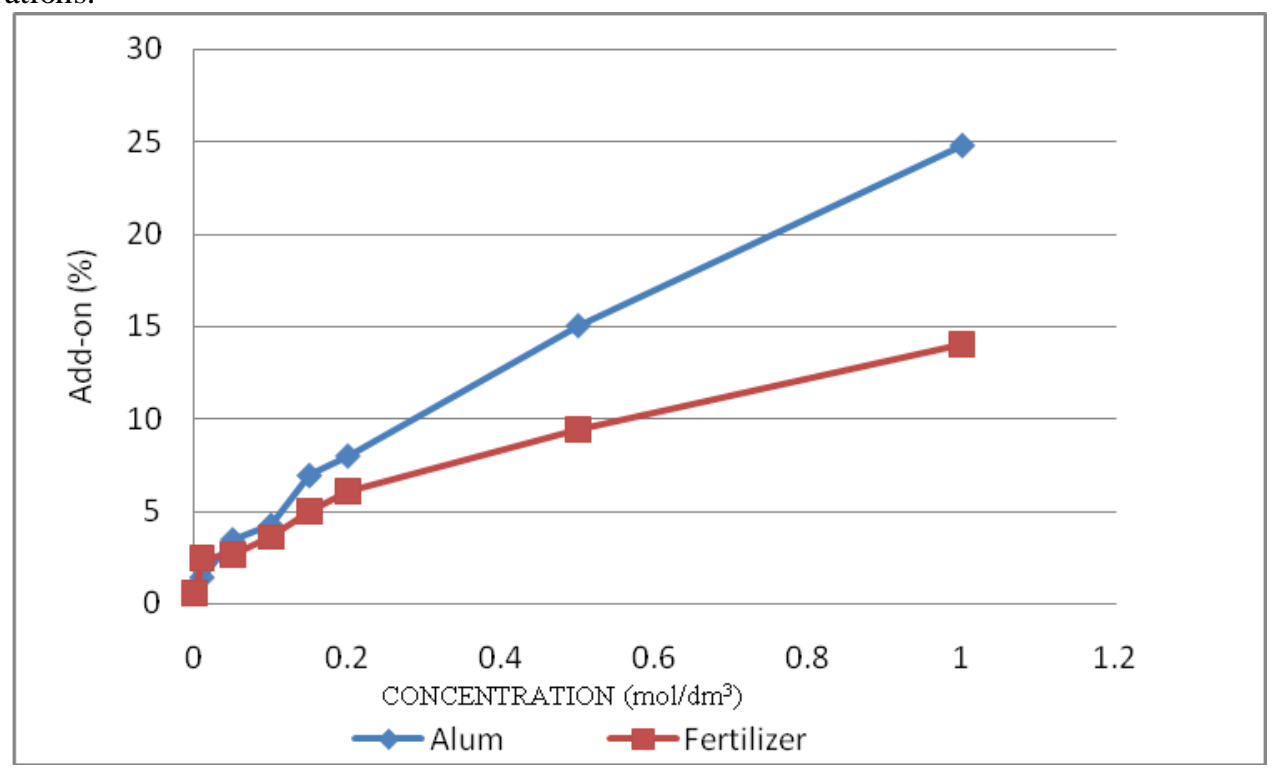

Fig. 1: The effect of concentration of F.R on the add-on for Schizachyrium sanguineum

It is observed (Fig.2) that these flame retardants delays ignition with respect to increase in concentration. The systematic reduction in the flame propagation rate (Fig.3), After Glow Time (fig.4) and Flame duration time (fig.5), with the flame-retardant treatment is as follows:

Potassium Aluminum Sulphate (Alum): At high temperatures, it decomposes according to the equation:

$\mathrm{K}_{2} \mathrm{SO}_{4} \cdot \mathrm{Al}_{2}\left(\mathrm{SO}_{2}\right)_{2} \cdot 24 \mathrm{H}_{2} \mathrm{O}=\mathrm{K}_{2} \mathrm{SO}_{4}+\mathrm{Al}_{2} \mathrm{O}_{3}+3 \mathrm{SO}_{3}+24 \mathrm{H}_{2} \mathrm{O}$.

Di-ammonium Hydrogen Phosphate (fertilizer): The flame-retardant mechanism of DAP is achieved according to the following mechanism:

$\left(\mathrm{NH}_{4}\right)_{2} \mathrm{HPO}_{4}=\mathrm{NH}_{3(\mathrm{~g})}+\mathrm{NH}_{4} \mathrm{H}_{2} \mathrm{PO}_{4(\mathrm{~s})}$

$\mathrm{NH}_{4} \mathrm{H}_{2} \mathrm{PO}_{4(\mathrm{~s})}=\mathrm{NH}_{3(\mathrm{~g})}+\mathrm{H}_{3} \mathrm{PO}_{4(\mathrm{l})}$

$2 \mathrm{H}_{3} \mathrm{PO}_{4}=\mathrm{P}_{2} \mathrm{O}_{5}+3 \mathrm{H}_{2} \mathrm{O}$.

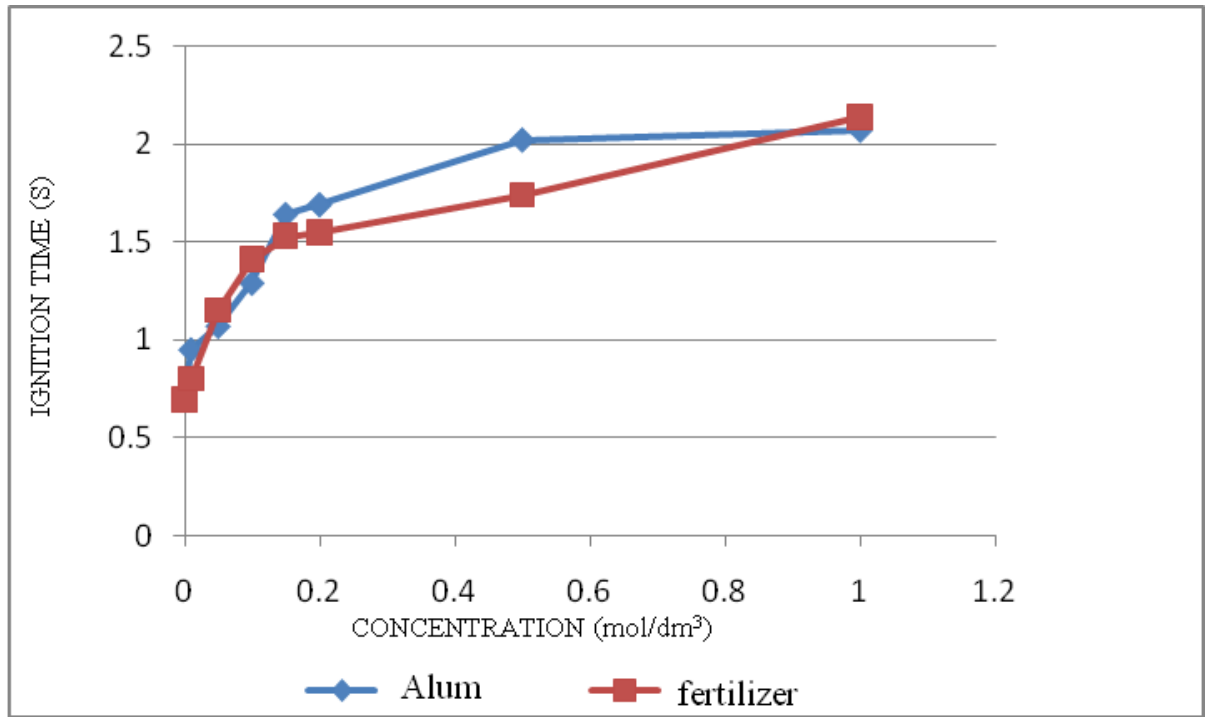

Fig.2: The effect of concentration of F.R on Ignition time for Schizachyrium sanguineum. 
The flame inhibiting property of Di-ammonium Hydrogen Phosphate and Potassium Aluminum Sulphate are interpreted in terms of the vapour, liquid and condensed phase mechanisms as the case may be. The gaseous products, $\mathrm{SO}_{3}, \mathrm{H}_{2} \mathrm{O}$ and $\mathrm{NH}_{3}$ dilute the combustible volatile pyrolysates of cellulose, thereby reducing their concentration in the flame zone. The evolution of water absorbs heat and thereby reduces the transport processes of heart conduction and fluid flow. $\mathrm{K}_{2} \mathrm{SO}_{4}$ and alumina $\left(\mathrm{Al}_{2} \mathrm{O}_{3}\right)$ are excellent heat conductors that deflect heat away from the burning surface. $\mathrm{H}_{3} \mathrm{PO}_{4}$ is a very viscous liquid which act as a film on the cellulose filbers, thereby damming up the issuing pyrolysate. Phosphorus-Oxy acids also catalyze cellulose pyrolysis via char formation. $\mathrm{P}_{2} \mathrm{O}_{5}$ has the ability of directing cellulose combustion to the production of carbon monoxide instead of carbon dioxide.

$5 \mathrm{C}+\mathrm{P}_{2} \mathrm{O}_{5}=5 \mathrm{CO}+2 \mathrm{P}$

In regard to equation (5), the exothermic reactivity of the system reduces and hence serves as fire extinguisher.

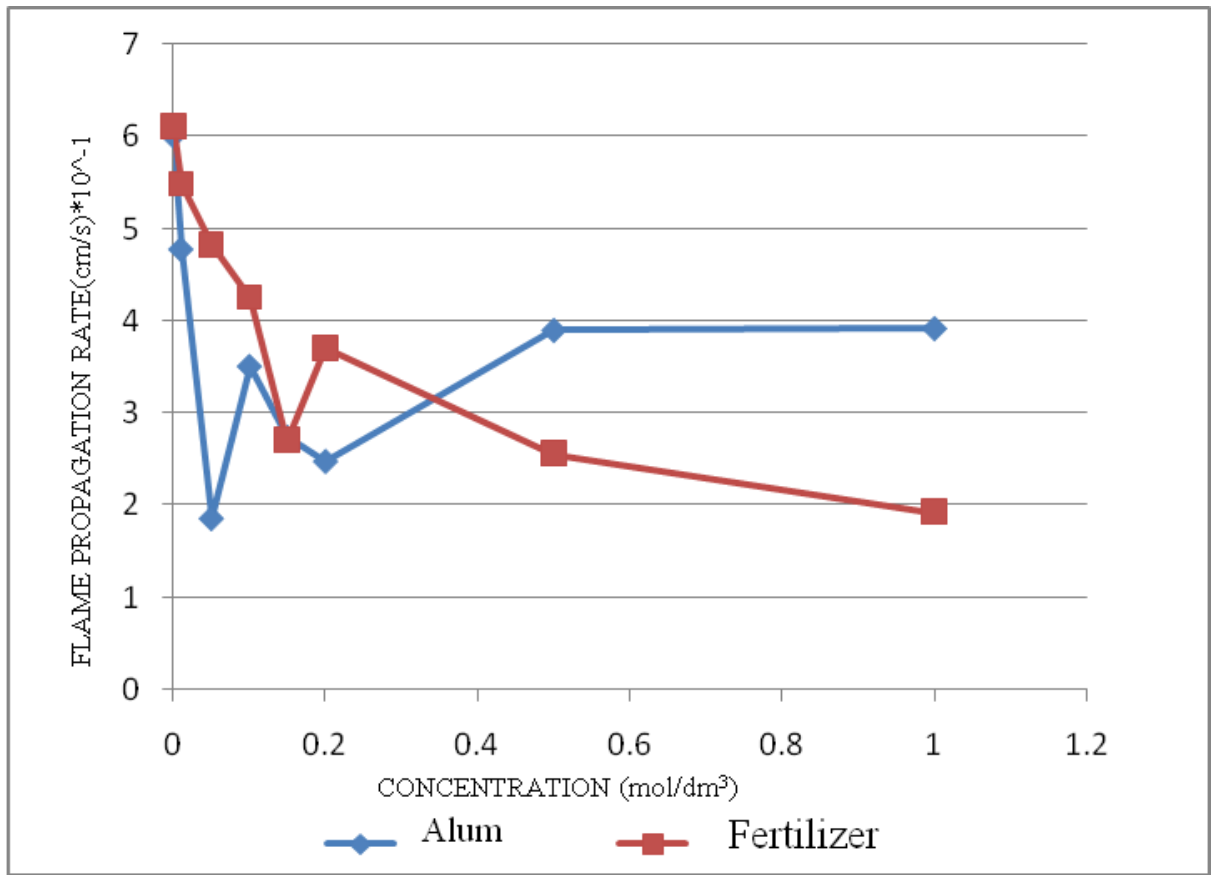

Fig. 3: The effect of concentration of F.R on F.P.R for Schizachyrium sanguineum.

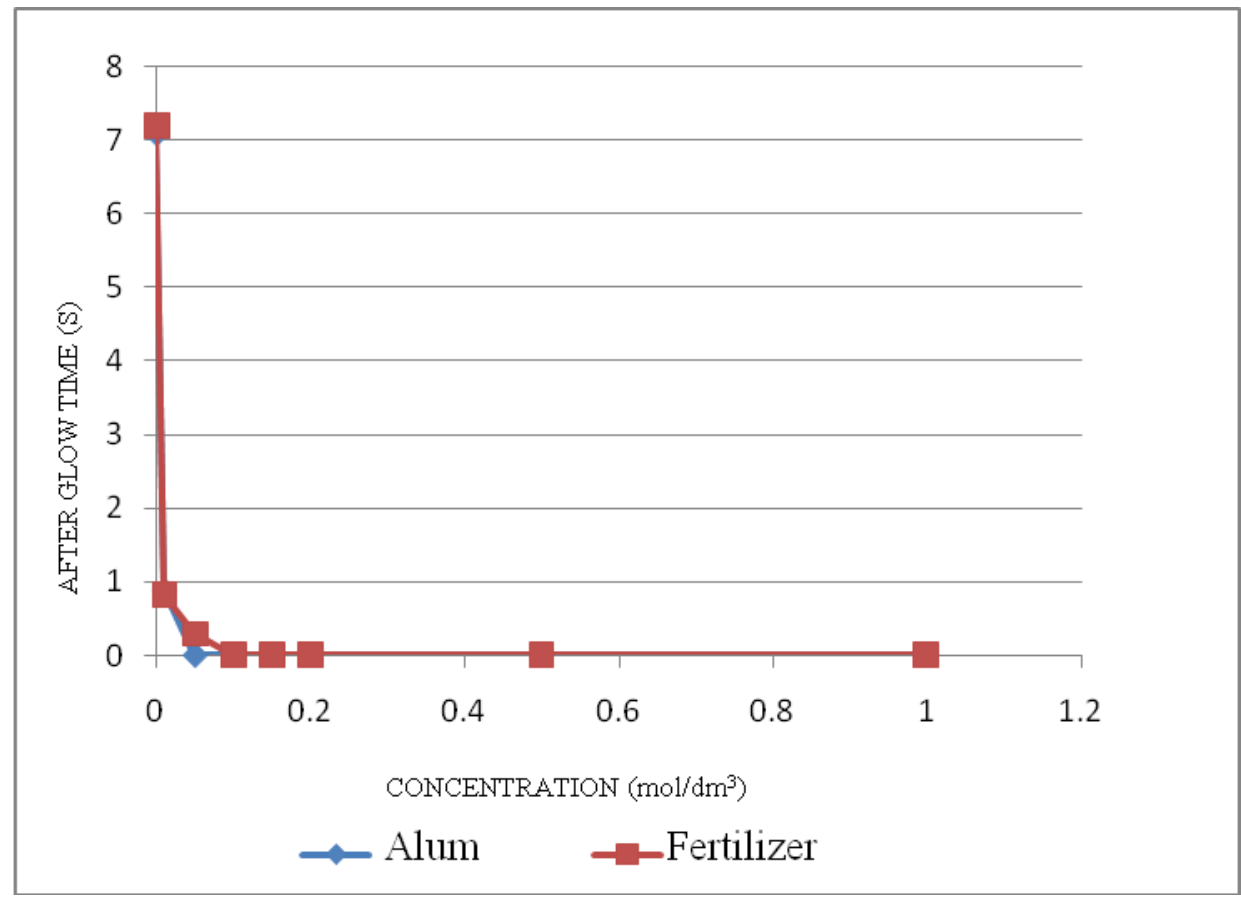

Fig.4: The effect of concentration of F.R on A.G.T for Schizachyrium sanguineum. 


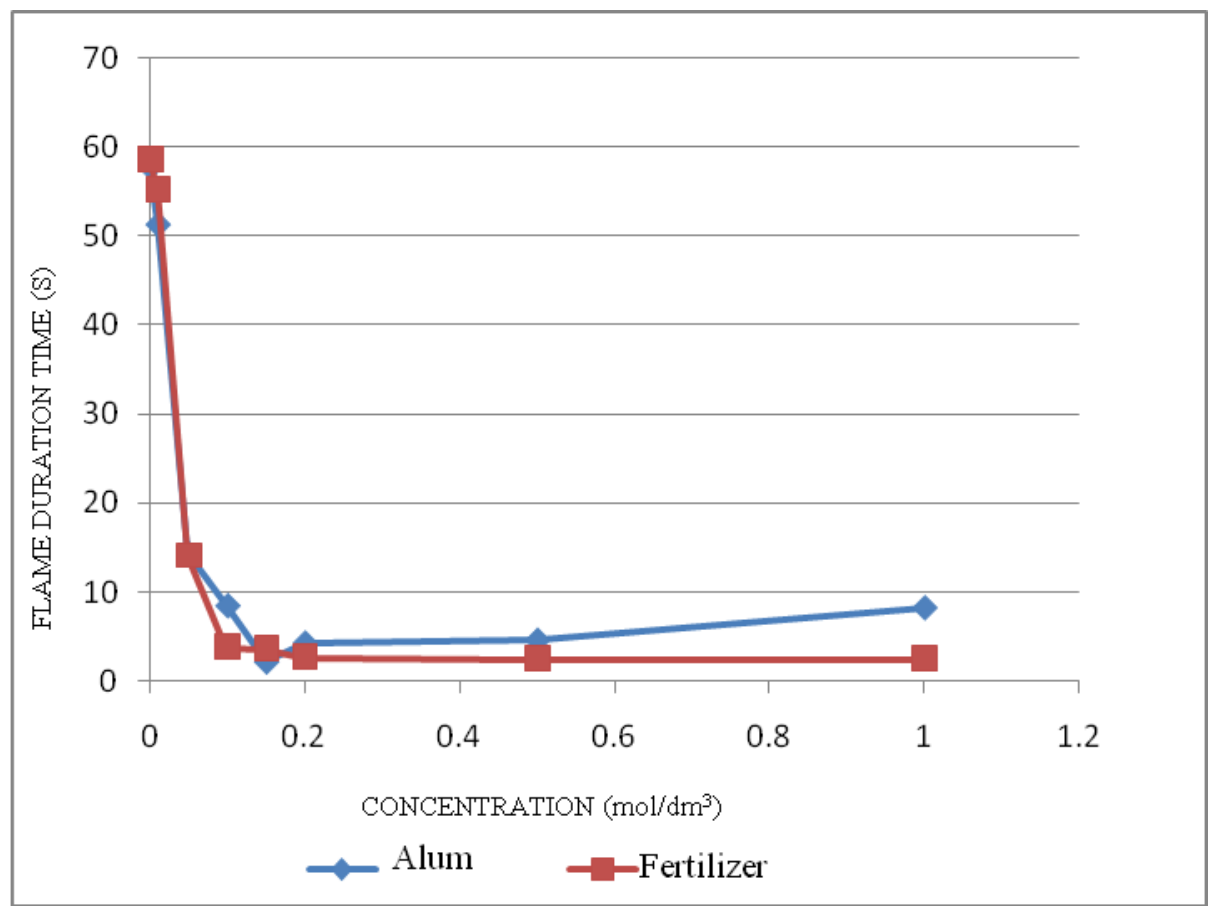

Fig.5: The effect of concentration of F.R. on F.D.T. for Schizachyrium sanguineum.

\section{CONCLUSION}

From the result of this investigation it is concluded that Potassium Aluminum Sulphate (Alum) and Diammonium Hydrogen Phosphate (fertilizer) compete with the chemistry of pyrolysis / combustion of this grass. Hence, it is clear that these two chemical compounds are suitable for treatment of thatch material to reduce its burning rate, increase its ignition time and to answer the 'call-for-help' on its flammability nature. It is important to note that thatch roof is constructed in layers, should the flame retardant leach from the top-most layer after a long exposure to rainfall, the underlying layer remains dry and intact. Nevertheless the aim of our application remains untouched since over $80 \%$ of house fire start from below and not from the top.

\section{REFERENCES}

[1] Ogogu J. Diogu, $30^{\text {th }}$ Annual Conference of the Nigerian Geographical Association, March 1987.

[2] McGhee \$ Co. Roof Thatchers, Thatching in North America Since1991. A Brief History of Thatch. http://www.thatching.com/Meghee.html. Retrieved June 4, 2012

[3] S.C. Odinma. Investigation of the effect of some flame-retardants on fire characteristics of roofing thatch, M.Sc. Thesis. Nnamdi Azikiwe University Awka, Nigeria, 2013.

[4] A. N. Eboatu and B. Garba, J. Appl. Polym. Sci. 39, (1990), 109-118

[5] A.N. Eboatu, I. Amanfo and I. Akpabio, "Effect of Flame Retardant Treatment on the Mechanical Properties of Some Tropical Timbers, Journal of Applied Polymer Science, 44: 1992, 239-242.

[6] T. L. Hill and T. W. Roven, J. Polym. Sci., 9, 1952, 93. 